\title{
OS IDOSOS MAIS VELHOS NO MEIO RURAL: REALIDADE DE VIDA E SAÚDE DE UMA POPULAÇÃO DO INTERIOR GAÚCHO ${ }^{1}$ THE OLDEST ELDERS IN RURAL LIFE: REALITY OF LIFE AND HEALTH OF A POPULATION OF THE GAÚCHO COUNTRYSIDE LOS ANCIANOS MÁS VIEJOS EN EL MÉDIO RURAL: REALIDAD DE VIDA Y SALUD DE UMA POBLACIÓN DE LO INTERIOR GAÚCHO
}

\author{
Eliane Pinheiro de Morais², Rosalina Aparecida Partezani Rodrigues ${ }^{3}$, Tatiana Engel Gerhardt ${ }^{4}$
}

\begin{abstract}
${ }^{1}$ Recorte da tese de doutorado "Envelhecimento no meio rural: condições de vida, saúde e apoio dos idosos mais velhos de Encruzilhada do Sul - Rio Grande do Sul”, defendida na Escola de Enfermagem de Ribeirão Preto (EERP) da Universidade de São Paulo (USP) em 2007.

${ }^{2}$ Doutora em Enfermagem. Professora da Escola de Enfermagem (EENF) da Universidade Federal do Rio Grande do Sul (UFRGS). Rio Grande do Sul, Brasil.

${ }^{3}$ Doutora em Enfermagem. Professora Titular da EERP/USP. Orientadora da tese. São Paulo, Brasil.

${ }^{4}$ Doutora em Antropologia Social. Professora Adjunto em Saúde Coletiva da EENF/UFRGS. Rio Grande do Sul, Brasil.
\end{abstract}

PALAVRAS-CHAVE: Envelhecimento. Saúde da população rural. Idoso de 80 anos ou mais. Saúde do idoso

KEYWORDS: Aging. Rural health. Aged, 80 and over. Health of the elderly.
RESUMO: Trata-se de estudo epidemiológico transversal com objetivo de descrever e analisar os dados demográficos, sócio-econômicos e as condições de saúde dos idosos com 80 anos ou mais, residentes no meio rural de Encruzilhada do Sul - RS. Para coleta dos dados dos 137 idosos foram realizadas entrevistas domiciliares entre março a junho de 2006. Os dados foram analisados empregando-se estatística descritiva e inferencial. A idade média das idosas foi de 84,1 (dp=3,8), e dos idosos, de 85,3 $(\mathrm{dp}=3,5)$. Quanto ao estado civil e à escolaridade, existe diferença significativa entre homens e mulheres, $80,0 \%$ são idosas e viúvas $(p<0,001)$, e $77,2 \%$ analfabetas $(p=0,013)$. O reumatismo e a hipertensão arterial são as morbidades mais referidas. O estudo contribui para dar maior visibilidade a essa parcela populacional, para compreensão do processo de envelhecimento e adequação das políticas públicas.
PALABRAS CLAVE: Envejecimiento. Salud rural. Ancianos de 80 años y más. Salud del anciano.
ABSTRACT: This cross-sectional epidemiological study aims to describe and analyze demographic and socioeconomic data and health conditions of elderly people of 80 years or more, residents in the rural area of Encruzilhada do Sul, RS, Brazil. The population consisted of 137 elderly people. The data was collected through interviews carried out at the participants' homes, between March and June of 2006. The data was analyzed using descriptive and inferential statistics. The mean age of the women was $84.1(\mathrm{SD}=3.8)$, and of the men $85.3(\mathrm{SD}=3.5)$. As to the marital status and years of study, there are significant differences between men and women; $80 \%$ of the women are widows $(p<0.001)$, and $77.2 \%$ are illiterate $(p<0.013)$. Rheumatism and hypertension are the most common morbidities. This study contributes to give greater visibility to this part of the population, towards better comprehension of the aging process and adequacy of public policies
Eliane Pinheiro de Morais Endereço: R. Eudoro Berlink, 219, Ap. 401

90.450-030 - Moinhos de Vento, Porto Alegre, RS, Brasil.

E-mail: eliane.morais@ufrgs.br epmorais@hotmail.com
Artigo original: Pesquisa

Recebido em: 15 de outubro de 2007 Aprovação final: 21 de maio de 2008 


\section{INTRODUÇÃO}

O envelhecimento é, hoje, uma realidade na maioria das sociedades desenvolvidas e em desenvolvimento, tornando-se temática relevante do ponto de vista científico e de políticas públicas, mobilizando pesquisadores e promotores de políticas sociais, na discussão do desafio que a longevidade humana está colocando para as sociedades.

Partindo da dificuldade de se estabelecer quando um indivíduo começa a envelhecer, vários autores postulam que o processo de envelhecimento faz parte de um contínuo que se inicia com a concepção e só termina com a morte.

Nesta linha, o envelhecimento é definido pela Organização Pan-Americana de Saúde e referendado pelo Ministério da Saúde como "um processo seqüencial, individual, acumulativo, irreversível, universal, não patológico, de deterioração de um organismo maduro, próprio a todos os membros de uma espécie de maneira que o tempo torne capaz de fazer frente ao estresse do meio-ambiente e, portanto aumente sua possibilidade de morte". ${ }^{1: 8}$

Um estudo latino-americano sobre o envelhecimento populacional chama atenção para os conceitos de idoso, velhice e envelhecimento como sendo uma construção social que varia segundo as culturas, países ou classes sociais, e que tem importantes implicações para a análise de uma região tão heterogênea como a América Latina, cujos países apresentam grandes desigualdades sociais. ${ }^{2}$

$\mathrm{O}$ aumento da expectativa de vida, principalmente nos países desenvolvidos, fez com que seja incorporada uma quarta etapa às já existentes. Esta vertente do pensamento contemporâneo tem seu expoente em Laslett que, em 1991, propôs os chamados princípios de Laslett, com a publicação do livro "A fresh map of life: the emergence of the third age". ${ }^{3}$

As idades postuladas pelo autor supracitado constituem atualmente uma vertente da gerontologia, em que os idosos muito idosos ou muito velhos, ou, ainda, com 80 anos ou mais, são pertencentes à quarta idade, que seria a etapa alusiva à fase de declinação, com maior dependência e acelerada perda das capacidades funcionais e cognitivas. ${ }^{2}$

Em quase todos os países do mundo, o grupo populacional que mais cresce é o de pessoas com idade igual ou superior a 80 anos, tendo a previsão de duplicação nos próximos dois decênios, o que representa uma mudança populacional sem precedentes. ${ }^{4}$
Existem previsões que os idosos serão responsáveis por quase $15 \%$ da população total em 2020 e, além disto, a proporção da população de 80 anos e mais, também está aumentando, alterando a composição etária dentro do próprio grupo. ${ }^{5}$ Atualmente existem cerca de 17 milhões de idosos no Brasil, e destes, $12,8 \%$ possuem mais de 80 anos de idade. Os idosos com 80 anos ou mais somam $1,1 \%$ da população brasileira. ${ }^{1}$

Os agravos de saúde de longa duração que acometem os indivíduos idosos têm na própria idade seu principal fator de risco, agrega-se ainda a idéia da baixa renda, advindas das aposentadorias ou da inexistência delas, uma vez que a situação socio-econômica influencia na saúde dos idosos, como mostra a análise dos dados da Pesquisa Nacional por Amostra de Domicílio (PNAD) de 1998. Os idosos com renda mais baixa apresentam piores condições de saúde, pior função física e menor uso dos serviços de saúde, e mostram que mesmo pequenas diferenças na renda mensal per capita são suficientes para estes resultados. ${ }^{6}$

Analisando os dados da pesquisa realizada no Rio Grande do Sul (RS) em 1997, observa-se que, da população de idosos entrevistada nas regiões urbanas, 66,22\% nasceram no meio rural e 32,83\% no meio urbano. Esse movimento migratório foi provocado pelo deslocamento da população em busca de melhores condições de vida, em razão das transformações ocorridas no estado na atividade agrícola, com a mecanização massiva no campo, especialmente na cultura de arroz e soja. ${ }^{7}$

A urbanização se faz sentir também nos pequenos municípios, como é o caso de Encruzilhada do Sul - RS. Analisando a população rural em relação a população total, foi constatado que em 1950 era de $89 \%$, reduzindo-se para $78 \%$ em 1970 , para $52 \%$ em 1991, e para $38 \%$ em $2000 .{ }^{8}$

A vila de Encruzilhada do Sul - RS foi elevada à categoria de cidade, devido ao seu crescimento, em 31 de março de 1938 e " [...] as condições de vida local em alguns aspectos melhoraram na primeira metade do século, porém estas mudanças não chegaram a ocorrer para a grande maioria da população. O grau de alfabetização, para residentes acima de 5 anos de idade, passou de 34\% em 1920 para 39\% em 1950. Em dez anos, o número de habitantes com alguma formação educacional completa aumenta 4 vezes, de 292 pessoas em 1940 para 1458 pessoas em 1950, enquanto o crescimento demográfico, num ritmo menor foi de $12 \%$. Neste período de transição, $90 \%$ dos habitantes ainda se estabeleciam na zona rural, apesar da zona urbana, 
que se expandia lentamente, apresentar melhores condições de domicílio". 9:127

Passado um século de intensas mudanças de ordem estrutural nos níveis mundial, nacional, regional e municipal, a cidade de Encruzilhada do Sul - RS chegou ao ano 2000 com o Índice de Desenvolvimento Humano, referente à qualidade de vida, de 0,76, valor este que, segundo o Programa das Nações Unidas para o Desenvolvimento de 2003, reflete o padrão de desenvolvimento médio, quando comparado com grande parte dos municípios gaúchos, que já apresentam valores considerados de elevado desenvolvimento. ${ }^{9}$

Atualmente o município de Encruzilhada do Sul - RS apresenta uma vasta extensão geográfica, $3.419 \mathrm{~km}^{2}, 13^{\circ}$ maior do RS, com uma elevada diversidade social em seu interior, tendo também uma grande importância histórica e cultural para a metade sul, assim como para o estado, em decorrência de sua localização e seu sistema produtivo predominante, baseado na pecuária. ${ }^{8}$

O fato dos idosos residirem em áreas rurais, faz com que suas vulnerabilidades sejam naturalmente acentuadas como mostra o estudo dos idosos de uma área rural colombiana onde é ressaltado que existem algumas características comuns, tanto em países desenvolvidos quanto em desenvolvimento, dentre eles o Brasil. Especificamente no envelhecimento rural, são as seguintes: "a média de rendimento dos velhos da área rural é consistentemente menor que os urbanos; os da área rural tem maiores problemas de saúde e tendem a ser mais severos que os urbanos; os da área rural consomem maior quantidade de álcool; ao mesmo tempo que os problemas de saúde mental não são facilmente tratados e de fato, os serviços de atenção a saúde são escassos, inacessíveis e mais custosos que em área urbana; o transporte público é mais necessário, mas muito menos disponíveis do que na área urbana, tanto intra como inter regional". 10:27

Encruzilhada do Sul é um dos municípios mais antigos do RS, e teve sua história marcada por constantes mudanças nas condições socioeconômicas, com predominância de estrutura fundiária concentrada e produção voltada à pecuária extensiva de corte. Estes fatos sugerem a existência de grandes desigualdades sociais e políticas, principalmente no meio rural. ${ }^{9}$
No primeiro estudo realizado no PROINTER*, em Encruzilhada do Sul - RS, foi ressaltado, dentre outras situações, que a população rural deste município encontra-se em franco processo de envelhecimento. Ao apontar esta situação, instigou-se à construção de uma questão de pesquisa, que alia um fato real sobre o envelhecimento rural, assim, uma curiosidade acadêmica ao interesse pessoal da pesquisadora na área empírica, além do fato da escassez de trabalhos com esta população. ${ }^{8}$

O presente artigo busca dar maior visibilidade para esta parcela populacional descrevendo e analisando os dados demográficos, sócioeconômicos e as condições de saúde dos idosos presentes na realidade de vida de idosos com 80 anos ou mais, residentes no meio rural de Encruzilhada do Sul - RS.

\section{MÉTODO}

A pesquisa caracteriza-se por ser um estudo epidemiológico descritivo, transversal, que explorou as condições sócio-demográficas e de saúde dos idosos da zona rural de Encruzilhada do Sul - RS.

Participaram do estudo todos os idosos cadastrados no Programa de Agentes Comunitários (PACs) e que preencheram os seguintes critérios de inclusão: morar na área rural; ter 80 anos ou mais de idade; aceitar participar da pesquisa; estar em micro-áreas atendidas por Agentes Comunitários de Saúde (ACSs) e estar cadastrado no PACs. Como critérios de exclusão foram considerados: não estar em casa após três tentativas de visita (por diferentes motivos, dentre eles, a hospitalização), falecer nos meses da coleta dos dados e mudar-se de residência para a cidade.

Com o início da pesquisa e a atualização dos cadastros, dos 154 idosos atendidos pelos ACSs em 2005, três haviam falecido no primeiro semestre de 2005, cinco faleceram no segundo semestre de 2005, ficando fora da população anteriormente estabelecida. Sendo assim, 146 idosos foi o número do início da coleta dos dados. Destes, dois faleceram nos meses de março e abril de 2006, três mudaram-se para a cidade e quatro não foram encontrados após as três visitas, totalizando como população efetiva deste estudo, 137 idosos com 80 anos ou mais de idade.

\footnotetext{
* Programa Interdisciplinar de Pesquisa: "Evolução e Diferenciação da Agricultura, Transformação do Meio Natural e Desenvolvimento Sustentável em Espaços Rurais do Sul do Brasil" do Programa de Pós-Graduação em Desenvolvimento Rural da Universidade Federal do Rio Grande do Sul.
} 
$\mathrm{Na}$ construção do instrumento de coleta de dados, as questões do instrumento do Projeto Saúde, Bem-Estar e Envelhecimento (SABE) na América Latina e Caribe** serviram de guia, cabendo à autora deste estudo as adequações ao contexto rural que se fizeram pertinentes. $\mathrm{O}$ instrumento foi pré-avaliado por uma especialista na área epidemiológica e sofreu alterações. O instrumento foi construído com questões estruturadas e pré-codificadas: dados sócio-demográficos (idade, sexo, estado conjugal, local de nascimento; cor da pele, religião, ocupação, escolaridade, aposentadoria, renda); condições de saúde e hábitos de vida (autopercepção e comparação da saúde, uso de medicação, uso de álcool e cigarro, atividades físicas, hábitos alimentares, hidratação, presença de patologias, deficiências auditivas e oftalmológicas, quedas, saúde bucal).

O inquérito domiciliar ocorreu no período de 20 de março a 30 de julho de 2006. Foi realizado por uma das pesquisadoras e pelos ACSs que atuam do meio rural do município, após quatro encontros para treinamento dos mesmos. Cada agente realizou duas entrevistas com idosos de 75 a 79 anos idade, para o estudo-piloto.

Os dados foram analisados empregando-se estatística descritiva e inferencial. Para análise estatística, foi utilizado o software Statiscal Package for the Social Sciences for Windows, versão 11.0. As variáveis categóricas foram descritas e analisadas através de freqüências absolutas e relativas, enquanto que as variáveis quantitativas foram descritas através de média e desvio padrão. Para avaliar a associação entre as variáveis categóricas, os testes qui-quadrado de Pearson e Exato de Fischer foram aplicados. Para as variáveis quantitativas de distribuição simétrica, em relação ao sexo, o teste $t$ de Student foi aplicado e, para as assimétricas, o teste de Mann-Whitney. O nível de significância adotado foi de $5 \%$, sendo considerados significativos valores de $\mathrm{p} \leq 0,05$.

Os princípios éticos foram obedecidos com relação ao acesso e análise dos dados, respeitando as normas de pesquisa em saúde referidas pela Resolução N 196/96 do Conselho Nacional de Saúde. ${ }^{11}$ Os indivíduos foram esclarecidos sobre os objetivos da pesquisa e assinaram o Termo de Consentimento Livre e Esclarecido para participar da mesma. O projeto de pesquisa foi submetido e aprovado pelo Comitê de Ética da Escola de Enfermagem de Ribeirão Preto da Universidade de São Paulo (Processo No 0629/2005).

\section{RESULTADOS E DISCUSSÃO}

A maioria dos idosos deste estudo, 94,2\%, nasceu e viveu grande parte ou a totalidade de suas vidas no meio rural, o que confere ao processo de vida e envelhecimento características peculiares e diferenciadas dos idosos do meio urbano que tenham nascido e vivido neste mesmo período.

A população de idosos do município é de 3.174, sendo que destes, 1.452 vivem no meio rural, com uma concentração de 868 (59,70\%) idosos com idade entre 60 a 69 anos; $431(29,64 \%)$ entre 70 a 79 e $155(10,66 \%)$ idosos com 80 anos ou mais de idade. ${ }^{12}$

A Tabela 1 refere-se aos dados demográficos e sócio-econômicos dos 137 idosos, destacando-se que a maioria se encontra na faixa etária compreendida entre os 80-84 anos. A idade média dos idosos foi de 84,5 anos, e a mediana, de 84,0 . A idade média dos idosos foi de 84,5 anos (dp 3,7$)$, sendo que a das mulheres foi de 84,1anos (dp 3,8) e dos homens 85,3 anos (dp 3,5). Há uma concentração de $122(89,1 \%)$ idosos na faixa etária compreendida entre os 80 aos 89 anos, enquanto que 15 (11,0\%) estão acima dos 90 anos.

Os idosos deste estudo possuem idades que estão entre os 80 anos e 96 anos, compreendendo um intervalo de 16 anos. Segundo a PNAD de 2004, na distribuição percentual dos grupos etários, 1,4\% da população do RS está na faixa dos 80 anos ou mais. ${ }^{13}$ Esta distribuição caracteriza um decréscimo numérico, intimamente ligado ao aumento da morbi-mortalidade nas idades mais elevadas, passando por um período de dependência e de necessidades de cuidados, antes de chegarem ao fim da vida. Idosos nestas condições são chamados de idosos frágeis ou débeis. ${ }^{4,14}$

Associado à redução das reservas biológicas e ao aumento da susceptibilidade para doenças e incapacidades, os idosos mais velhos que vivem em áreas rurais possuem um risco adicional, em conseqüência da distância a que estão dos serviços de saúde, o que pode ser agravado em decorrência do isolamento geográfico. ${ }^{15}$

\footnotetext{
** Lebrão, M.L.; Duarte, Y.A de O. (Org).Projeto SABE no município de São Paulo: uma abordagem inicial. Brasília,
} DF: Organização Pan-Americana de Saúde, 2003 
Tabela 1 - Distribuição da freqüência das variáveis demográficas e sócio-econômicas segundo o sexo dos idosos mais velhos de Encruzilhada do Sul - RS, 2006.

\begin{tabular}{|c|c|c|c|c|c|c|c|}
\hline \multirow{3}{*}{$\begin{array}{l}\text { Variáveis demográficas } \\
\text { e sócio-econômicas }\end{array}$} & \multicolumn{4}{|c|}{ Sexo $(n=137)$} & \multirow{2}{*}{\multicolumn{2}{|c|}{ Total }} & \multirow{3}{*}{$\mathrm{p}^{*}$} \\
\hline & \multicolumn{2}{|c|}{ Feminino } & \multicolumn{2}{|c|}{ Masculino } & & & \\
\hline & $n$ & $(\%)$ & $n$ & $(\%)$ & $\mathbf{n}$ & (\%) & \\
\hline \multicolumn{8}{|l|}{ Idade (em anos) } \\
\hline $80-84$ & 56 & $(70,0)$ & 24 & $(30,0)$ & 80 & $(58,3)$ & $0,128^{a}$ \\
\hline $85-89$ & 23 & $(54,8)$ & 19 & $(45,2)$ & 42 & $(30,7)$ & \\
\hline $90-94$ & 6 & $(46,2)$ & 7 & $(53,8)$ & 13 & $(9,5)$ & \\
\hline $95-100$ & 2 & $(100,0)$ & 0 & $(0,0)$ & 2 & $(1,5)$ & \\
\hline \multicolumn{8}{|l|}{ Cor da pele } \\
\hline Branca & 73 & $(63,5)$ & 42 & $(36,5)$ & 115 & $(83,9)$ & $0,848^{a}$ \\
\hline Preta & 8 & $(72,7)$ & 3 & $(27,3)$ & 11 & $(8,0)$ & \\
\hline Parda & 5 & $(55,6)$ & 4 & $(44,4)$ & 9 & $(6,6)$ & \\
\hline Amarela & 1 & $(50,0)$ & 1 & $(50,0)$ & 2 & $(1,5)$ & \\
\hline \multicolumn{8}{|l|}{ Estado civil } \\
\hline Solteiro & 7 & $(58,3)$ & 5 & $(41,7)$ & 12 & $(8,8)$ & $<0,001^{a}$ \\
\hline Casado/união estável & 12 & $(30,0)$ & 28 & $(70,0)$ & 40 & $(29,2)$ & \\
\hline Viúvo & 68 & $(80,0)$ & 17 & $(20,0)$ & 85 & $(62,0)$ & \\
\hline \multicolumn{8}{|l|}{ Escolaridade $^{\dagger}$} \\
\hline Analfabeto & 44 & $(77,2)$ & 13 & $(22,8)$ & 57 & $(41,9)$ & $0,013^{a}$ \\
\hline Só assina o nome & 11 & $(47,8)$ & 12 & $(52,2)$ & 23 & $(16,9)$ & \\
\hline Alfabetizado & 31 & $(55,4)$ & 25 & $(44,6)$ & 56 & $(41,2)$ & \\
\hline \multicolumn{8}{|l|}{ Onde aprendeu $u^{\ddagger}$} \\
\hline Em casa & 12 & $(55,2)$ & 11 & $(47,8)$ & 23 & $(41,1)$ & $0,203^{a}$ \\
\hline $\mathrm{Na}$ escola rural & 17 & $(63,0)$ & 10 & $(37,0)$ & 27 & $(48,1)$ & \\
\hline Na escola da cidade & 2 & $(66,7)$ & 1 & $(33,3)$ & 3 & $(5,4)$ & \\
\hline Outro & 0 & $(0,0)$ & 3 & $(100,0)$ & 3 & $(5,4)$ & \\
\hline \multicolumn{8}{|l|}{ Religião } \\
\hline Nenhuma & 7 & $(63,6)$ & 4 & $(36,4)$ & 11 & $(8,0)$ & $0,581^{a}$ \\
\hline Católica & 65 & $(61,3)$ & 41 & $(38,7)$ & 106 & $(77,4)$ & \\
\hline Evangélica & 13 & $(72,2)$ & 5 & $(27,8)$ & 18 & $(13,1)$ & \\
\hline Espírita & 2 & $(100,0)$ & 0 & $(0,0)$ & 2 & $(1,5)$ & \\
\hline \multicolumn{8}{|l|}{ Aposentadoria } \\
\hline Sim & 80 & $(62,0)$ & 49 & $(38,0)$ & 129 & $(94,2)$ & $0,331^{a}$ \\
\hline Não & 7 & $(87,5)$ & 1 & $(12,5)$ & 8 & $(5,8)$ & \\
\hline \multicolumn{8}{|l|}{ Tem outra renda } \\
\hline Sim & 40 & $(65,6)$ & 21 & $(34,4)$ & 61 & $(44,5)$ & $0,785^{a}$ \\
\hline Não & 47 & $(61,9)$ & 29 & $(38,1)$ & 76 & $(55,5)$ & \\
\hline \multicolumn{8}{|c|}{ Recebem ajuda econômica de outros } \\
\hline $\operatorname{Sim}$ & 12 & $(63,2)$ & 7 & $(36,8)$ & 19 & $(14,1)$ & $1,000^{a}$ \\
\hline Não & 73 & $(62,0)$ & 43 & $(38,0)$ & 116 & $(85,9)$ & \\
\hline \multicolumn{8}{|l|}{ Trabalho atual } \\
\hline $\operatorname{Sim}$ & 38 & $(55,1)$ & 31 & $(44,9)$ & 69 & $(50,8)$ & $0,068^{a}$ \\
\hline Não & 48 & $(71,6)$ & 19 & $(28,4)$ & 67 & $(49,2)$ & \\
\hline $\begin{array}{l}\text { * Na hipótese de que a casuíst } \\
\text { a Teste Qui-Quadrado de Pear } \\
\text { † Uma (1) mulher não soube r } \\
\text { †Consideradas as respostas do }\end{array}$ & & ória simp & & ma popul & & terísticas & nilares. \\
\hline
\end{tabular}


Na distribuição por sexo às mulheres predominam sobre os homens, assim como na faixa etária dos 80 aos 84 anos, encontra-se a maior concentração destas, 56. Dos 85-89 e 90- 94 anos o número de mulheres e de homens é equivalente, entretanto, acima dos 95 anos de idade encontramse apenas mulheres. A distribuição por sexos do contingente dos idosos deste estudo segue a tendência apresentada nos diversos estudos e nas pesquisas de base populacional sobre envelhecimento, ou seja, um maior número de mulheres 87 para 50 de homens, numa proporção de 100 mulheres para 57,5 homens. Segundo informações do Instituto Brasileiro de Geografia e Estatística (IBGE), no Brasil, para cada 100 mulheres idosas, existem 78,6 homens idosos. ${ }^{13}$ É importante ressaltar que os dados do IBGE são da população total, sem discriminar área urbana e rural. O diferencial por sexo entre os idosos, acentuado nos últimos anos, pode ser explicado pela diferença no ritmo de crescimento das populações idosas, feminina e masculina, causado principalmente pela situação de mortalidade diferencial por sexo.

Outro fator que influencia no maior número de mulheres idosas mais velhas no campo, foi a migração masculina, rural-urbana, ocorrida na fase produtiva da vida, ou seja, nos adultos jovens, estando as razões para tal movimento enraizadas em dinâmicas socioeconômicas e culturais. Na migração urbano-rural, os idosos geralmente são independentes financeira e funcionalmente. Apenas 3,6\% dos idosos do estudo vivem no meio rural a menos de 5 anos, enquanto a grande maioria movimentou-se dentro desse meio durante toda sua existência.

Desde a década de 50 do século XX, a realidade vivida no Brasil é da masculinização do envelhecimento no meio rural, pois a migração à procura de trabalho nas cidades e a oferta de empregos nos setores de serviços e de comércio estão absorvendo mais a mão-de-obra feminina. ${ }^{16}$ Essa seletividade por sexo e idade na migração é devida à modernização da agricultura (aumento de produtividade e diminuição de empregos), a maneira como as jovens estão sendo socializadas, a divisão do trabalho nos estabelecimentos familiares (mulheres com tarefas rotineiras e pouco valorizadas) e a exclusão das mulheres da herança da terra. ${ }^{17}$ Em outros países, como Portugal e França, onde se observa o mesmo processo, diferenciando-se apenas na questão temporária, pois o envelhecimento da população nesses países iniciou há mais tempo. ${ }^{18}$
Quanto ao estado civil, houve uma associação estatística significativa com o sexo $(p<0,001)$, sendo que, há uma predominância de viúvos, a maioria mulheres. Entretanto, nos casados ou com união estável inverte-se os números, isto é, a maioria é de homens. A distribuição dos solteiros por sexo apresenta-se mais equilibrada.

O estado civil dos idosos mais velhos remete a uma discussão de gênero e cultura, quando se observa que as mulheres são na maioria viúvas e, os homens casados. A viuvez, no Brasil, segundo dados do IBGE é vivenciada com mais freqüência nas mulheres quando comparado aos homens, uma vez que o Censo 2000 encontrou 1.149.157 homens viúvos e 5.082.116 mulheres, numa proporção de cinco mulheres viúvas para um homem viúvo. ${ }^{12}$ Esta situação é devida ao fato das mulheres casarem mais jovens que seus esposos, possuírem maior longevidade e dificilmente voltarem a casar. ${ }^{19}$

As mulheres, uma vez viúvas, vivem sós. No total de 97 idosos mais velhos que viviam sós em 32 comunidades rurais coreanas, foram encontrados 10 homens e 87 mulheres, sendo a morte dos esposos a causa de viverem sós. ${ }^{20}$

Um estudo sobre as vivências do envelhecimento e da viuvez com idosas do RS, revela que as razões para não casarem novamente são diversas, como o "respeito ao esposo falecido, receio de repetir experiências negativas, perda da liberdade conquistada, resistência dos filhos e a possível perda do poder em relação aos filhos" ${ }^{19: 183}$

Verifica-se que, quanto à escolaridade, a maioria, 58,8\%, é de analfabetos e/ou assinam o nome, que demonstra a baixa escolaridade em ambos os sexos. Na relação sexo e escolaridade, houve uma associação estatística significativa $(p=0,013)$, prevalecendo nos homens os melhores índices de escolaridade.

Com relação à escolaridade, o índice de analfabetos ou que apenas assinam o nome é de $58,8 \%$ mulheres. Na pesquisa com idosos colombianos a média de escolaridade foi de 2,1 anos. $\mathrm{O}$ estudo ainda chama atenção para o fato da baixa escolaridade ser um fator de deterioração geral da saúde nas áreas rurais. ${ }^{10}$

A história da colonização e da formação do município pode explicar o elevado índice de idosos mais velhos de cor branca, 83,9\%, em razão de grande parte ser de origem açoriana e indígena, e também pela chegada, em 1910, de imigrantes poloneses nessa região. ${ }^{9}$ Ainda segundo dados do IBGE, a Região Sul é constituída por $80,8 \%$ de pessoas brancas. ${ }^{12}$ 
A maior parte dos idosos, 129 , recebe aposentadoria rural, e destes, 115 são aposentados por idade, nove por tempo de serviço e cinco por invalidez. Observa-se que a maioria dos idosos mais velhos recebe algum tipo de benefício, sendo este provindo de aposentadoria por idade, tempo de serviço, ou ainda por invalidez. Muitas idosas recebem também pensões deixadas por seus cônjuges, que uma vez viúvas, estas passam a receber a pensão e a aposentadoria do esposo e, na maioria das vezes, é realizado o inventário, cabendo a viúva a metade das terras, que geralmente passa a ser cultivada pelos filhos, pagando a ela o arrendamento. Chama-se atenção para a mudança de papel da viúva na família, pois esta situação financeira gera um empoderamento da mesma. ${ }^{17}$

Ao analisar os efeitos não-esperados das mudanças da legislação brasileira, relativas a benefícios não-contributivos dirigidos à população idosa rural, foi verificado que esses efeitos incluem impacto positivo na renda familiar, redução da pobreza, bem como mudanças nos arranjos familiares. A cobertura dos benefícios da previdência social torna-se quase universal quando os indivíduos atingem o intervalo etário de 70 a 79 anos. ${ }^{21}$

Essa realidade brasileira não é compartilhada por outros países da América Latina, a exemplo da Colômbia, onde a "jubilación no existe en el campo". 10:47
A carência de seguridade social obriga a trabalhar até idades muito avançadas e também por tradição, pois os homens devem permanecer trabalhando, porque deixar de trabalhar é sinônimo de inatividade e anúncio de decadência e desgraça. Esse sentimento também é compartilhado pelos idosos do presente estudo, quando a metade deles informa que ainda realizam pequenos trabalhos no ambiente doméstico, como os cuidados com a horta e animais domésticos.

Abordar a temática da velhice rural, na Argentina, implica necessariamente fazer referência à pobreza rural, devido a diversas razões, dentre elas a grande extensão das unidades agrárias, as estâncias, pois confinaram os campesinos nos minifúndios, com terras de baixa fertilidade e geralmente sem direitos à propriedade das mesmas. Entre os moradores das áreas rurais que padecem agudamente em situações precárias, estão os idosos, cujos familiares mais jovens migraram para as cidades. ${ }^{22}$

Assim como nos demais estados e municípios brasileiros, também em Encruzilhada do Sul - RS, o impacto da aposentadoria rural junto às famílias pobres foi fundamental para a transformação das relações no meio rural, uma vez que o dinheiro oriundo das aposentadorias é usado para comprar alimentos para o lar, para enviar crianças à escola, investir em tecnologias agrícolas e garantir a sobrevivência de muitas famílias. ${ }^{23}$

Tabela 2 - Auto-avaliação da saúde segundo o sexo dos idosos mais velhos. Encruzilhada do Sul-RS, 2006.

\begin{tabular}{|c|c|c|c|c|c|c|c|}
\hline \multirow{2}{*}{ Condições de saúde } & \multicolumn{2}{|c|}{$\begin{array}{l}\text { População total } \\
\quad(n=137)\end{array}$} & \multicolumn{2}{|c|}{$\begin{array}{c}\text { Feminino } \\
(n=87)\end{array}$} & \multicolumn{2}{|c|}{$\begin{array}{l}\text { Masculino } \\
(n=50)\end{array}$} & \multirow[t]{2}{*}{ p } \\
\hline & $\mathbf{n}$ & $(\%)$ & $\mathbf{n}$ & $(\%)$ & $\mathrm{n}$ & $(\%)$ & \\
\hline \multicolumn{8}{|c|}{ Auto-avaliação da saúde } \\
\hline Ótima & 8 & $(5,8)$ & 2 & $(25,0)$ & 6 & $(75,0)$ & $0,111^{\mathrm{a}}$ \\
\hline Boa & 45 & $(32,8)$ & 28 & $(62,2)$ & 17 & $(37,8)$ & \\
\hline Regular & 64 & $(46,7)$ & 41 & $(64,1)$ & 23 & $(35,9)$ & \\
\hline Ruim & 15 & $(10,9)$ & 12 & $(80,0)$ & 3 & $(20,0)$ & \\
\hline Péssima & 5 & $(3,6)$ & 4 & $(80,0)$ & 1 & $(20,0)$ & \\
\hline \multicolumn{8}{|c|}{$\begin{array}{l}\text { Comparação da saúde com outras } \\
\text { pessoas }\end{array}$} \\
\hline Ótima & 24 & $(17,6)$ & 12 & $(50,0)$ & 12 & $(50,0)$ & $0,552^{2}$ \\
\hline Boa & 64 & $(47,1)$ & 42 & $(65,6)$ & 22 & $(34,4)$ & \\
\hline Regular & 39 & $(28,7)$ & 25 & $(64,1)$ & 14 & $(35,9)$ & \\
\hline Ruim & 8 & $(5,9)$ & 6 & $(75,0)$ & 2 & $(25,0)$ & \\
\hline Péssima & 1 & $(0,7)$ & 1 & $(100,0)$ & 0 & $(0,0)$ & \\
\hline \multicolumn{8}{|c|}{$\begin{array}{l}\text { Comparação da saúde atual com a de } \\
12 \text { meses atrás }\end{array}$} \\
\hline Melhor & 15 & $(10,9)$ & 11 & $(73,3)$ & 4 & $(26,7)$ & $0,178^{a}$ \\
\hline Igual & 79 & $(57,7)$ & 45 & $(57,0)$ & 34 & $(43,0)$ & \\
\hline Pior & 43 & $(31,4)$ & 31 & $(72,1)$ & 12 & $(27,9)$ & \\
\hline
\end{tabular}

a Teste Qui-Quadrado de Pearson. 
$\mathrm{Na}$ Tabela 2, referente às condições de saúde e alguns hábitos de vida; observa-se que 64 dos idosos consideram sua saúde regular, 45 boa, 15 ruim, oito ótima e cinco péssima.

Quando avaliada a autopercepção de saúde em relação às faixas etárias por sexo, foi possível observar que os idosos que se consideram com menos saúde estão na faixa etária de 80-84 anos, tanto para os homens como para as mulheres. Houve associação limítrofe $(p=0,063)$ entre a faixa etária e a questão da comparação da saúde com a de outras pessoas da mesma idade nos homens, sendo que os que referiram sua saúde como ótima, se encontram na faixa etária de 85-89 anos.

$\mathrm{Na}$ zona cafeeira da Colômbia, $47 \%$ dos idosos se sentem saudáveis. Dentro do pequeno grupo de $12 \%$ que referiram sua saúde como muito ruim, encontram-se os idosos de 80 anos ou mais, ${ }^{10}$ o que pode ser traduzido como quanto mais se aproximam do fim da vida, piores são suas percepções a respeito da saúde. Dos idosos coreanos que vivem sós em comunidades rurais, $67,0 \%$ se percebem com boa saúde e $27,8 \%$, com saúde ruim. Esse estudo não classificou a auto-avaliação de saúde segundo idade ou sexo. ${ }^{20}$ Os idosos mais velhos são mais numerosos no grupo que referiu a saúde como ruim, e a pior percepção da saúde é maior entre os homens, quando comparados às mulheres. ${ }^{6}$

Um resultado positivo foi referente ao hábito de fumar, pois 16 dos idosos mantêm esse hábito na idade avançada, contabilizando uma média de 55,9 anos deste hábito. Encontrou-se uma associação significativa $(p<0,001)$ com o sexo, dos que já fumaram, a maioria é de homens, e hábito de não ingerir álcool mostrou uma associação significativa $(\mathrm{p}<0,001)$ quanto ao sexo, pois dos que não ingerem álcool, 77,1\% são mulheres. Estes resultados diferem dos outros estudos urbanos, que apresentam prevalência do tabagismo entre os idosos do sexo masculino, que pode estar associada a questões culturais, pelo fato das mulheres aderirem mais tardiamente ao hábito de fumar. Já em relação ao hábito de ingerir bebidas alcoólicas, há a prevalência dos homens, tanto no caso de beber no passado, como beber eventualmente, assemelhando-se ao achados dos demais estudos.?

As deficiências relacionadas à audição e à visão são fatores limitantes para a vida cotidiana dos idosos mais velhos, que são agravadas quando somadas com a idade, devido à catarata, glaucoma, degeneração macular e retinopatia diabética. ${ }^{23}$ Essas deficiências foram encontradas nos idosos, pois a maioria referiu ter problemas de visão. Para 53 deles o problema é corrigido com o uso de lentes com melhora e 33 precisariam, mas não possuem esse recurso.

Quanto à deficiência auditiva, menos da metade dos idosos referiu possuí-la e, destes, apenas três usam aparelho auditivo. Alguns reconhecem a necessidade do uso, o que pode ser avaliado como positivo, pois demonstram ter conhecimento da existência dessa ferramenta, embora os motivos para não possuí-la não tenham sido perguntados. Nos idosos do RS foi encontrada como causa do problema auditivo a idade $(16,7 \%)$, doenças de ouvido $(5,95 \%)$, falta de recursos econômicos para o tratamento $(3,54 \%)$ e falta do aparelho $(0,4 \%){ }^{7}$ É bem possível que, se tivesse sido feita a mesma questão para os idosos deste estudo, as respostas se assemelhassem, resguardada a questão da idade, uma vez que esses dados foram com idosos com 65 anos ou mais.

Quanto à presença de dentes, encontramos uma associação estatisticamente significante $(p=0,037)$ com o sexo, onde dos 96 que não possuem nenhum dente, 68 são mulheres e 28 são homens. Os homens possuem mais dentes, pois 16 possuem mais da metade. A saúde oral dos idosos mais velhos é um fator preocupante, pois mais da metade informou não ter mais nenhum dente. Os resultados mostraram que as mulheres idosas possuem menos dentes que os homens. O edentulismo (ausência de dentes) geralmente tem prevalência elevada entre os idosos, e as duas principais causas são as cáries radiculares e a doença periodontal. Embora haja uma relação direta entre edentulismo e idade, tem aumentado o número de idosos que procuram preservar seus dentes, não recorrendo ao tratamento praticado no passado, isto é, a extração. ${ }^{24}$

Observamos ainda que, do total dos idosos, 34 tiveram algum tipo de queda, sendo que as mulheres caíram mais que os homens, pois, dos que sofreram quedas, 25 são mulheres. Os idosos mais velhos do meio rural podem ser ainda mais susceptíveis a quedas e pequenos acidentes domésticos, devido a situações encontradas no próprio ambiente em que vivem. Dos idosos que informaram alguma queda, apenas cinco tiveram fraturas do tipo fechadas, tendo prevalecido ferimentos do tipo escoriações. As mulheres do estudo tiveram mais quedas quando comparadas aos homens. Ao compararem por grupos de idade, os maiores caidores, em ambos os sexos, foram os do grupo da maior idade, ou seja, com 80 anos ou mais. ${ }^{10}$ 
Na população total da pesquisa que considera que o problema de saúde interfere nas atividades diárias, 42 idosos referem que reumatismo está em primeiro lugar, 39 os problemas de coluna, 37 a insônia, 30 a pressão alta, 30 a catarata, 27 os problemas de nervos, e 23 os problemas cardíacos. Das doenças não-transmissíveis indagadas, a hipertensão arterial foi citada por praticamente a metade dos idosos, seguido por problemas de coluna, reumatismo, insônia, catarata e má circulação. Apesar da hipertensão arterial estar presente na vida da metade dos idosos, não é a morbidade que mais interfere nas atividades diárias. Este lugar é ocupado pelo reumatismo, seguido de problemas na coluna e insônia, reforçando o paradigma da funcionalidade como indicador de saúde mais significativo nessa população, do que a mera presença de doenças. ${ }^{25}$

\section{CONCLUSÕES}

A população que vive nas zonas rurais está envelhecendo à semelhança dos que vivem nas zonas urbanas, porém, é possível observar nos resultados dos estudos com esta população que as diferenças existentes vão além dos aspectos quantitativos e dimensionais, apontando para uma realidade onde predomina a pobreza, isolamento, baixos níveis educacionais, residências mais precárias, limitações de transporte, problemas crônicos de saúde e distância dos recursos sociais e de saúde, dentre outras.

Estas dificuldades são sentidas com maior intensidade na população de idosos mais velhos, devido a crescente fragilidade com a aproximação do fim da vida. As mulheres são em maior número nesta faixa etária da população, ou seja, entre os idosos com mais de 80 anos. Neste estudo, as mulheres são maioria nas faixas etárias iniciais ( 80 a 84 anos). Nas faixas seguintes, o número entre mulheres e homens aproxima-se, e as diferenças significativas entre os sexos destacam-se no estado civil, na escolaridade e na percepção da saúde.

A família dos idosos que vivem no meio rural é a principal fonte de recurso e apoio, uma vez que os serviços sociais e de saúde praticamente inexistem, o que se traduz em um aumento considerável do risco para os idosos que não contam com este recurso. A família é um fator protetor do envelhecimento rural e, como tal, deve ser foco de políticas públicas sociais e de saúde adequadas às particularidades desta população.

\section{REFERÊNCIAS}

1 Ministério da Saúde (BR), Secretaria de Atenção à Saúde, Departamento de Atenção Básica. Envelhecimento e saúde da pessoa idosa. Brasília (DF): MS; 2006 [acesso em 2007 Mar 22]. Disponível em: http://portal.saude.gov.br/portal/arquivos/ pdf/caderno_do_idoso_2007.pdf

2 Chackiel J. El envejecimiento de la población latinoamericana: ¿hacia una relación de dependencia favorable? Santiago (CL): Centro Latinoamericano y Caribeño de Demografía; 2000.

3 Caldas CP. Quarta idade: a nova fronteira da gerontologia. In: Papaléo Netto M. Tratado de gerontologia. 2a ed. São Paulo (SP): Atheneu; 2007. p.163-73.

4 Organización Mundial de la Salud, Organización Panamericana de la Salud. Salud de las personas de edad: envejecimiento y salud: un cambio de paradigma: $122^{a}$ sección. Washington (USA): OMS/ OPAS; 1998.

5 Camarano AA. Envelhecimento da população brasileira: uma contribuição demográfica. Rio de Janeiro: Instituto de Pesquisa Econômica Aplicada; 2002

6 Lima-Costa MF, Barreto S, Giatti L. Condições de saúde, capacidade funcional, uso de serviços de saúde e gastos com medicamentos da população idosa brasileira: um estudo descritivo baseado na Pesquisa Nacional por Amostra de Domicílios. Cad. Saúde Pública. 2003 Maio/Jun; 19 (3): 735-43 [online] [acesso em 2006 Mar 11]. Disponível em: http:// www.scielo.br/pdf/csp/v19n3/15877.pdf

7 Conselho Estadual do Idoso (RS). Os idosos do Rio Grande do Sul: estudo multidimensional de suas condições de vida [relatório de pesquisa]. Porto Alegre (RS): Conselho Estadual do Idoso; 1997.

8 Ribas RP. As características socioculturais na promoção (ou limitação) de capacitações: a análise das tradições Encruzilhadenses (Encruzilhada do Sul/RS) [monografia]. Porto Alegre (RS): UFRGS/ Departamento de Ciências Econômicas; 2004.

9 Ribas RP, Miguel LA. A história e o desenvolvimento socioeconômico de Encruzilhada do Sul - RS periodizado segundo a abordagem dos sistemas agrários. REDES. 2004 Set-Dez; 9 (3): 111-44.

10 Gómez Montes JF, Curcio Borrero CL. Envejecimiento rural: el anciano en las zonas cafeteras colombianas. Manizales (CO): Universidad de Caldas; 2004.

11 Ministério da Saúde (BR), Conselho Nacional de Saúde, Comissão Nacional de Ética em Pesquisa. Resolução No 196 de 10 de outubro de 1996: diretrizes e normas regulamentadoras de pesquisa envolvendo seres humanos. Brasília (DF): MS; 1996.

12 Instituto Brasileiro de Geografia e Estatística. Censo demográfico 2000: agregado por setores censitários dos resultados do universo: Região Sul. v.4. Rio de Janeiro (RJ): IBGE; 2002. 
13 Instituto Brasileiro de Geografia e Estatística. Perfil dos idosos responsáveis pelos domicílios no Brasil: 2000. Rio de Janeiro (RJ): IBGE; 2006 [acesso em 2006 Ago 01]. Disponível em: http://www.ibge. gov.br/home/estatistica/populacao/perfilidoso/ default.shtm

14 Ishizaki T, Yoshida H, Kumagai S, Watanabe S, Shinkai S, Suzuki T, et al. Active life expectancy base don activities of daily living for older people living in a rural community in Japan. Geriatr. Gerontol. Int. 2003 Dec; 3 (s1): S78-82 [online] [acesso em 2005 Jan 23]. Disponível em: http:/ / www.blackwell-synergy. com/toc/ggi/3/s1

15 Hinck S. The lived experience of oldest-old rural adults. Qual. Health Res. 2004 July; 14 (6): 779-91.

16 Bercovich A. Características regionais da população idosa no Brasil. Rev. Bras. Estud. Popul. 1993 Jan-Dez; 10 (1/2): 123.

17 Brumer A. Gênero e agricultura: a situação da mulher na agricultura do Rio Grande do Sul. Rev. Estud. Fem. 2004 Jan-Abr; 12 (1): 205-27.

18 Wall K. Famílias no campo: passado e presente em duas freguesias do Baixo Minho. Lisboa (PT): Dom Quixote; 1998.

19 Buaes CS, Doll J. Aprende a ser viúva: narrativas de mulheres idosas no meio rural. Rev. Kairós. 2005; 8 (2): $171-88$.

20 Ahn YH, Kim MJ. Health care needs of elderly in a rural community in Korea. Public Health Nurs. 2004 Mar; 21 (2): 153-61 [online] [acesso em 2007 Mar 12]. Disponível em: http://www.blackwell-synergy. com/doi/pdf/10.1111/j.0737-1209.2004.021209.x

21 Beltrão KI, Camarano AA, Mello JL. Mudanças nas condições de vida dos idosos rurais brasileiros: resultados não-esperados dos avanços da seguridade rural. Rio de Janeiro (RJ): Instituto de Pesquisa Econômica Aplicada; 2005.

22 Oddone MJ, Aguirre MB. La problemática social de la vejez en el medio rural. Rev. Kairós. 2005; 8 (2): 139-70.

23 World Health Organization. Envelhecimento ativo: uma política de saúde. Brasília (DF): OPAS; 2005.

24 Pucca Junior GA. Saúde bucal do idoso. In: Papaléu Neto M. Tratado de Gerontologia. 2a ed. São Paulo (SP): Atheneu; 2007. p.521-35.

25 Francisco CM. Estudo dos fatores preditores de envelhecimento sem incapacidade funcional entre idosos em velhice avançada no município de São Paulo [dissertação]. São Paulo (SP): USP/Escola de Enfermagem; 2006. 
